\title{
Exploration of the Professional Basic Course and the Teaching Team Construction of Computer Science Graduate
}

\author{
Meng Han ${ }^{1}$, Wenyu Chen ${ }^{2}$, Dagmawi Moges ${ }^{2}$ \\ ${ }^{1}$ School of Political Science and Public Administration, University of Electronic Science \& Technology of China, P.R. CHINA \\ ${ }^{2}$ School of Computer Science and Engineering, University of Electronic Science \& Technology of China, P.R. CHINA
}

Received 7 June 2017 • Revised 18 September 2017 • Accepted 20 October 2017

\begin{abstract}
The construction of the postgraduate teaching team and the construction of high level teachers are an important prerequisite for improving the teaching quality and teaching reform of postgraduate students, and also one of the driving forces to guarantee the sustainable development of education. This article combined with the state, society to the current demand and developing trend of computer science and technology industry, by setting up reasonable professional foundation course, the teachers troop construction, cultivating young teachers, using high quality materials, determining the reasonable teaching content, the use of advanced teaching methods, using reasonable teaching evaluation system, auxiliary teaching resources platform, the construction of computer science and technology professional basic course teaching team, to provide a strong guarantee for the cultivation of the subject, a graduate student, also hope to provide some useful reference for engineering college graduate education.
\end{abstract}

Keywords: computer graduate, professional basic course, teaching team

\section{INTRODUCTION}

As an important way to cultivate high-level talents, postgraduate education is a practical problem that must be faced in improving the quality of talents in computer science and technology (computer science). In the national medium and long-term education reform and development plan outline (2010-2020) " (The official Xinhua news agency, 2010) and" national medium and long-term talent development plan outline (2010-2020) (The official Xinhua news agency, 2010) explicitly pointed out that improve the quality of graduate education is the important measures to promote our country towards education power.

As a leader of education, a university of China and a graduate student of Chinese university, the University of China has clearly required 985 universities to reform and cultivate the model and cultivate innovative talents (Baidu library, 2010). "Graduate teaching team support plan" project in 985 colleges and universities in the "985 project" overall planning as one of the major construction projects of graduate education, research and actively explore innovative talent training mode, further perfect and improve the graduate student curriculum system; The teaching team is built around teaching materials, professional basic courses and teaching teams.

"Degree regulations of the People's Republic of China" and "interim measures for its implementation degree regulations of the People's Republic of China" regulation, the purpose of the graduate student teaching is to cultivate high quality talents, so you must complete the course. Therefore, the cultivation of students' creative thinking and practical ability in basic curriculum teaching has become one of the basic requirements of postgraduate teaching (Jiang zongli, 2004, Liu changan, 2009).

After four years of exploration and practice, in view of the university of electronic science and technology of computer college graduate training objectives, by setting up reasonable professional foundation course (including practical courses), cultivate outstanding young teachers, improve the quality of the teachers of teachers, write a high level of graduate courses, establish a perfect and reasonable evaluation system, etc., to ensure the quality of graduate education. 


\section{Contribution of this paper to the literature}

- Explore new teaching methods and methods to implement curriculum content.

- Taking a scientific research as the lead to improve innovation ability.

- Explore the way of course assessment and evaluate the learning effect comprehensively.

- Construct a new teaching system based on computer science graduate student.

University of electronic science and technology of computer basic teaching team was established in early 2012, professional team construction in the process, some problems, mainly includes:

\section{Specialized Foundation Curriculum is not Reasonable}

The current situation of computing technology and technological development cannot be reflected in a timely manner; the knowledge of curriculum system is old, and it is insufficient for students' innovative quality and ability. In the absence of practical teaching courses, there are only practical courses related to professional basic courses in embedded system experiment. The graduate student's basic knowledge of hardware of the computer science and technology is very weak, basic don't understand the latest development of computer hardware and technology direction and dynamic, let alone have a good grasp of the current hardware design.

\section{The Content of Professional Basic Courses is not Reasonable}

Professional foundation course content with sufficient different in content and course content of undergraduate course teaching has the similarity of different degree; Because the content of the new course is mainly determined by the teacher, the lack of effective mechanism guarantees the rationality of the teaching content and the continuity of the content of the undergraduate teaching. The course involved a small amount of hardware content and experimental content

\section{Lack of Professional Basic Curriculum Teachers}

Professional foundation course teachers' lack of the teaching team has not yet formed perfect teaching team; the teaching effect of young teachers is not obvious and outstanding.

\section{The Textbook Needs to be Updated}

The teaching materials need to update the part of the course teaching materials have been used more than 3 years, need to be revised; Some of the courses are currently using self-compiled notes, which need to be improved to be a formal teaching material; Some textbooks have insufficient practice content and lack of relevant theories and technologies of the latest development. The relevant teaching materials are not perfect and immature.

\section{The Evaluation Method is Single}

Evaluation approach is a single evaluation of student achievement is relatively simple, mainly in the form of the final exam undertake to the student assessment; Lack of reasonable evaluation system for students; The assessment of teachers is also vague (the method of assessment of undergraduate teaching is adopted by the college), which lacks the effective evaluation mechanism for postgraduate teaching work. Lack of a reasonable standard of reward and punishment.

\section{Other Problems}

Team each rules and regulations are still in trial stage; the teaching and research activities have not been institutionalized and standardized; Lack of supporting teaching platform and other teaching resources (such as problem bank, teaching website, etc.).

\section{RESEARCH DESIGN AND APPROACH}

Graduate students in university of electronic science and technology in the graduate cultivation target should have solid foundation of theory, engineering professional knowledge, understand the latest frontier disciplines and dynamic, to master the discipline of modern experimental methods and skills, and can adapt to the needs of scientific progress and social development, with independent ability to engaged in the work of scientific research or engineering technology. Also should have the rigorous scientific attitude, good cooperation spirit and strong 
communication skills, competence and scientific research in the fields of computer, software, hardware, system development, as well as the field of computer teaching work, to become the leader in the future to lay a solid foundation, technical director

Combining theory and practice, the traditional teaching model combining teaching with modern research teaching, build a comprehensive training graduate students' knowledge, quality and ability of computer foundation course teaching system. Choose according to professional training objective, students one's deceased father grind and employment information and feedback by teachers and so on the actual situation, in the process of computer professional graduate student curriculum developed the following train of thought :

It is necessary for graduate students to further develop creative and logical thinking skills. Therefore, more complete professional theoretical knowledge is required. The ability of computational thinking, algorithm design and analysis is the basic professional quality of computer science graduate. The relevant theory is the basis of computer science and is an important distinction between computer science and other subjects.

In computer science, specific experiments are needed to verify the correctness and performance of theories and methods. It also requires the ability of system engineering in engineering practice. Therefore, the system engineering implementation capability is an important part of practice ability, the cultivation of the ability of system project, need to preset related experimental courses in the curriculum, improve students' ability to use knowledge.

To maintain standardization and consistency of cultivating the ability of graduate students, through the construction of computer teaching steering committee of graduate students and its tenet is subject oriented, not only to let students possess a complete knowledge system, and requires extensive solicitation of the state, society for computer talents abilities, qualities, skills and knowledge requirements, continuously improve the computer course system.

Follow the principle of professional foundation courses and the overall mentality, the three professional direction of computer science and technology, computer system structure, computer software and theory, computer application technology) set up public professional foundation courses, and a large number of elective courses according to their professional direction. Combined with the actual situation of the college of computer science and engineering, computer professional graduate student course is divided into two groups (teaching team is also divided into two): computer science and technology and information security course group. Computer science and technology curriculum group: finite automata theory, formal methods, algorithm design and analysis, and statistical learning theory and application, the neural network theory and application, advanced computer system, embedded system, the operating system kernel technology, system design - from the chip to the system. Information security curriculum group: information security mathematical foundation, modern cryptography, security protocol and standard.

\section{RESULTS}

For graduate professional basic course teaching with computers, benign operation, support the entire training system in construction of teaching material, for traction, to train the ability of graduate students as the goal, updating the teaching contents, enrich the content of the theory of depth and engineering practice, according to the related theory and technology at home and abroad the latest developing trend of setting frontier technology academic lectures, enrich the content of the teaching material, improve the practicability of teaching materials.

To cultivate high-level talents as the goal, based on cohesion and the basis of the existing in the teaching of undergraduate course (pay attention to the differences and continuity), reference to domestic and foreign teaching content, on the basis of computer science and technology discipline talents social needs, consider the connection with other course, science set up the course content.

Course content also need to consider the difference between the undergraduate and graduate courses content, Thurber of master and doctor to elective courses content, the difference between the new curriculum and course content arrangement, hardware experiment content Settings, and so on.

In the teaching method, the teaching method combined with classroom teaching and extracurricular practice should be fully developed, which effectively cultivates the students' theory and practice ability

In the teaching activities, teaching method improvement, formation and undergraduates of different teaching methods, according to the characteristics of the graduate students, the research-oriented teaching method, through the guide students to a certain scientific research or engineering design implementation, inspire students' thinking, consciously to guide the students in research and engineering thinking in learning the knowledge necessary to understand and use. To integrate the scientific thought process (such as cognitive method and other thoughts) into the knowledge structure of students, strengthen the teaching of the formation of knowledge structure, and attach importance to the source of ideas. At the same time, it points out the intrinsic connection of knowledge and guides students' thorough analysis of the problem. 
Efforts to find out how teaching can evolve from "imparting knowledge" to the process of "discovering knowledge" as the core process, cultivate the innovation consciousness and thinking habits of graduate students. Specific can let students learn the teacher recommended references, preset will discuss problems, let the students before the class group to research and thinking of problems, let the students in the classroom report to other students in the form of academic report, presided over by the teacher to discuss again, hold the direction of the discussion, and only to explain new knowledge points involved, the rest of the knowledge application should be completed by students themselves during the discussion.

The proper use of modern technology means starting from the course content, through the existing multimedia and field programming methods to improve the teaching effect. In the traditional teaching of blackboard books, the teaching of basic theories and the derivation of formula, it is easier for graduate students to keep up with the teaching rhythm, which is easier to understand and the teaching effect is good. Multimedia courseware is informative and can be combined with pictures, animations and videos in a relatively vivid and vivid form, which is good for the teaching of cutting-edge science and application examples. In addition, through the preset good application framework, lets the student in the classroom to complete certain knowledge of program implementation, not only can let the students to deepen the understanding of knowledge, also can further improve the practical ability of students.

Through a combination of courses in the field of scientific development, to introduce students to the latest progress and research direction is the industry's latest technology and products, and improve the graduate students learning interest in technology and scientific research; With all kinds of high quality authoritative review reports, the latest progress of academic articles, and the interest of the postgraduate students to participate in scientific research, the postgraduate students should establish rigorous scientific research accomplishment.

Give play to the role of scientific research to guide, make full use of the resources of college scientific research teams, features and advantages, the academic and scientific research achievements, and their academic ideas and research methods applied to the course construction, practice teaching and classroom teaching, to ensure that the course content of frontier and fresh; At the same time, the required academic leaders and the backbone of the college teaching courses in the form of lectures, implement scientific research training plan(Yang Jianwei, et al.,2016), guide the graduate students to participate in scientific research and innovation activities, and a series of measures to promote the cultivation of innovative talents and scientific research and the benign interaction between the teaching experiment system construction.

In addition to normal training requirements, special training programs should be carried out for certain cuttingedge courses. Through the special training program of the course, the postgraduate students should strengthen the theoretical cultivation of the course and explore the application of technology. Special students are required to report to combine the scientific research project of participation, on the basis of a series of research, references, and to preliminary after graduation design thinking and design, for the next step of research activities to lay the good foundation.

Always set up based on division, the concept of human resources is the first resource, the teachers' strict requirements, strict training, strict management, strengthening the construction of teaching staff, build a solid platform for the development of teams and discipline. The construction of the team includes two aspects: steady growth and horizontal improvement. In addition to the academic level, teachers should be able to systematically and scientifically impart their thinking methods, scientific attitudes and scientific research styles to graduate students.

Young teachers have a certain advantage over senior teachers in the aspects of knowledge and the completeness of scientific research methods, so they are the main force for the implementation of research-oriented teaching. However, young teachers lack the perfect methodology and experience of teaching, and make up for the lack of experience and methods through the teaching of senior teachers, which is an important and urgent task for the construction of teaching teams. For the cultivation of young teachers, the teaching training plan and target requirements of young teachers can be established to determine the teaching objectives of young teachers.

The postgraduate course examination needs to break the only score theory and comprehensively and comprehensively evaluate the learning effect of students (Enver Tatar et al., 2014) In the original course assessment, only one test or a course paper was used to evaluate students' academic performance. This method of assessment of the only score can only lead students to the pre-examination and the question of the sea tactics, and neglect the training of the ability of the curriculum. However, the postgraduate training is different from that of middle school students and undergraduates, and the research and practice teaching are dominant. Therefore, the practice, design and research in the curriculum design should be the main component in the final course grade. In particular, academic discussion, scientific research and project plan design, and relevant competition results can be used as final assessment methods. 
The team establishes the responsibility system at all levels and formulates the corresponding responsibility system, which shall be carried out after the review by the college graduate teaching steering committee. The team teaching quality responsibility teacher is responsible for supervising and ensuring the overall teaching quality of the whole course teaching team. Demonstrative teaching is responsible for the demonstration teaching of teachers' organization famous teachers; Group leader is responsible for the coordination and organization of course group of each course in the teaching and researching activities, such as the course of the construction of teaching material planning, course content between cohesion and organization of work, the responsibility of the course the teacher is in charge of the organization of the course of compiling textbooks, constituting the outline of the syllabus and the experimental teaching, the laboratory construction and development, course website construction and other related work. For student assessment method, form and content, exam is determined by the curriculum group discussion, and the of each course in the curriculum group is responsible for the teacher to discuss, for students in the course of the assessment method of the consistency and continuity, and ensure that students in the learning focus for scientific research and engineering practice ability exercise, rather than the final test scores. We will explore the way and content of the teaching effect of the course, improve the teacher's evaluation and reward and punishment mechanism, and keep the teacher's enthusiasm into the teaching work.

In addition, the excellent backbone teachers to famous university abroad study, through the "teachers' academic support plan of go abroad" to send outstanding teachers training in famous universities abroad, learning the advanced teaching method and theory, and the combination of teaching and scientific research as well as the curriculum system setting, etc.

\section{DISCUSSION AND CONCLUSION}

Fully grasp the teaching graduate curricula of computer science and technology characteristics, in the three aspects of knowledge, quality and ability, unifying the theory and practice, teaching and traditional teaching model of modern research teaching fusion, constructing new teaching system based on computer science graduate student; Draw lessons from foreign well-known colleges and universities computer high-end talent training content framework, combining with the current demand in the area of the country, the society for the computer industry and development trends, by setting up reasonable professional foundation course, using high quality materials, determine reasonable teaching content, the use of advanced teaching methods, teachers team construction, training of young teachers, the use of reasonable teaching evaluation system, auxiliary teaching resources platform, the construction of the university of electronic science and technology of computer professional graduate student curriculum teaching team, emphatically on the application of computer science graduate student knowledge, ability, and the theory and practice of combining basic quality training, ensure the quality of the students.

\section{REFERENCES}

Baidu library. (2010). The ministry of education, ministry of finance about accelerate the world first-class university and the construction of high level research university [EB/OL]. Retrieved on 9 September 2017 from http://wenku.baidu.com/view/858914878762caaedd33d406.html

Jiang, Z. (2004). Master of Computer Science and Technology Postgraduate study. Computer Education, (Z1), 72-77.

Jiang, Z. (2004). The Relationship between the Form of Computer Science and Postgraduate Training. Degree and Postgraduate Education, 24(11), 11-15.

Liu, C., \& Wen, G. (2009). College Teaching Team Construction Strategy Analysis. Chinese Adult Education, 32(04), $52-56$.

Tatar, E., Akkaya, A., \& Kağızmanlı, T. B. (2014). Trends in Dissertations Involving Technology-Assisted Mathematics Instruction: The Case of Turkey. Eurasia Journal of Mathematics, Science E Technology Education, 10(6), 547-558. doi:10.12973/eurasia.2014.1216a

The official xinhua news agency. (2010). The national medium and long-term education reform and development plan (2010-2020) [EB/OL]. Retrieved on 6 September 2017 from http://www.gov.cn/jrzg/201007/29/content_1667143.htm

Tthe official xinhua news agency. (2010). The national medium and long-term talent development plan (2010-2020) published [EB/OL]. Retrieved on 6 September 2017 from http://www.gov.cn/jrzg/201006/06/content_1621777.htm

Yang, J., Zhu, A., Zhang, Y., \& Zhao, C. (2016). The Construction and Practice of Classified Talent Cultivation System Combining with Professional Certification. Eurasia Journal of Mathematics, Science E Technology Education, 12(8), 2187-2197. doi:10.12973/eurasia.2016.1419a

\section{http://www.ejmste.com}

